\title{
Entrepreneurship and attention deficit/hyperactivity disorder: a large-scale study involving the clinical condition of ADHD
}

\author{
Daniel A. Lerner • Ingrid Verheul • Roy Thurik
}

Accepted: 1 December 2017 /Published online: 15 May 2018

(C) The Author(s) 2018

\begin{abstract}
A growing conversation has emerged linking ostensibly dark or pathological individual-level characteristics to entrepreneurship. Attention deficit/hyperactivity disorder (ADHD) is among the most central and emblematic. Recent studies have made great strides - articulating the theoretical relevance of ADHD-type behavior in entrepreneurship and suggesting a positive link consistent with narratives in the popular press. However, quantitative studies have yet to empirically examine ADHD in line with its theoretical roots and definition - as a clinical disorder. The
\end{abstract}

\section{A. Lerner}

Deusto Business School, Bilbao, Bizkaia, Spain

e-mail: daniel.lerner@colorado.edu

D. A. Lerner

Universidad del Desarrollo, Santiago, Chile

I. Verheul $(\bowtie)$

Department of Strategic Management \& Entrepreneurship,

Rotterdam School of Management, Erasmus University

Rotterdam, Rotterdam, The Netherlands

e-mail: iverheul@rsm.nl

R. Thurik

Department of Applied Economics, Erasmus School of

Economics, Erasmus University Rotterdam, Rotterdam,

The Netherlands

e-mail: thurik@ese.eur.nl

R. Thurik

Montpellier Business School (Labex Entrepreneurship),

Montpellier, France

\section{R. Thurik}

Erasmus University Rotterdam Institute for Behavior and Biology (EURIBEB), Rotterdam, The Netherlands present paper contributes by providing a theoreticallyempirically aligned test of the connection between the condition of ADHD and entrepreneurial intention and action. Based on a large-scale data collection effort $(N=$ 9869) and cross-sectional methodology, the results find a positive connection between clinical ADHD and entrepreneurial intentions as well as entrepreneurial action. This grounds prior research on ADHD and entrepreneurship, indicating that individuals with ADHD are indeed more likely to not just espouse entrepreneurial intentions, but also to initiate business venturing. Considering the design, it suggests a self-selection toward entrepreneurship in individuals with ADHD (before potentially being a choice of last resort).

Keywords Attention deficit/hyperactivity disorder . ADHD · Nascent venturing - Entrepreneurial intentions . Entrepreneurial action · Entrepreneurship

\section{JEL Classification L26}

\section{Introduction}

By the end of the twentieth century, the entrepreneurship literature had built a body of knowledge on logical, generally positive, factors associated with business venturing such as human capital, financial capital, cognitive biases, and traditional traits differentiating entrepreneurs (Shane 2003). Building on that tradition, in the twentyfirst century, scholars have made great strides in advancing entrepreneurship theory-covering many other 
factors associated with venturing such as regulatoryfocus (Tumasjan and Braun 2012; Hmieleski and Baron 2008), affect and passion (Baron et al. 2012; Cardon et al. 2012; Gielnik et al. 2017). Recently, a relatively new and growing conversation has emerged - that involving conventionally dark or pathologized constructs that may be positively associated with entrepreneurship. Among the most prominent, and previously suggested in the popular press (Archer 2014; The Economist 2012), is attention deficit/hyperactivity disorder (ADHD). Characterized by disinhibition, ADHD is indicated by impulsivity, hyperactivity, and problems with attentional regulation (APA 2013).

The theoretical and practical relevance of the above to entrepreneurship has recently been discussed (Verheul et al. 2015, 2016; Thurik et al. 2016; Wiklund et al. 2016, 2017, 2018; Lerner 2016; Lerner et al. 2018a, b, c; Miller and Le Brenton-Miller 2016). In particular, a number of studies drawing on the ADHD literature have emerged, suggesting a positive association between ADHD-related behavior and entrepreneurship, including an increased likelihood of entrepreneurial intentions (Verheul et al. 2015), venturing (Verheul et al. 2016), and entrepreneurial orientation (Thurik et al. 2016). These and related studies provide an important basis for the present investigation. In essence, they deal with behavioral tendencies that at the high end of the spectrum might be indicative of ADHD or of other disorders. With limited exception (discussed later), recent empirical research, while grounded in the clinical construct and literature of attention deficit/hyperactivity disorder, has yet to empirically examine ADHD - a diagnosed clinical condition. In other words, while predicated on prior research on the (clinical) condition of ADHD, the emerging entrepreneurship research has yet to examine whether the condition of ADHD is significantly linked to a higher propensity for entrepreneurial intentions and action. We contribute to recent theory about a positive ADHD - entrepreneurship link by providing a simple theoretically - empirically aligned test of the connection between ADHD and entrepreneurship.

The present work offers a number of contributions. It foments the emergent scholarly interest in the link between mental conditions and entrepreneurship (e.g., Wiklund et al. 2018) by focusing on a common condition that affects millions of adults worldwide (de Graaf et al. 2008), and that may be over-represented in entrepreneurial environments. With the overarching aim of testing whether ADHD is indeed linked to entrepreneurship, we go beyond recent research relating behavior that might be indicative of ADHD to entrepreneurship (Lerner 2016; Verheul et al. 2015, 2016; Thurik et al. 2016; Wiklund et al. 2017). Based on the reported large-scale study involving attention deficit/ hyperactivity disorder, we test whether ADHD is linked to an increased propensity for both entrepreneurial intentions and action. Grounding the aforementioned, and in conjunction with related entrepreneurship research (e.g., Lerner et al. 2018a, c), this work offers a novel basis for entrepreneurship theory, future research, and practice.

\section{Attention deficit/hyperactivity disorder}

\subsection{ADHD - the condition}

Attention deficit/hyperactivity disorder is a common clinical condition, defined by impulsive, hyperactive, and inattentive behavior (APA 2013), affecting individuals of all ages worldwide. With a full discussion of clinical diagnostic criteria beyond the scope of this paper, for ADHD to exist, the impulsive, hyperactive, and inattentive behavior must be pervasive, enduring, and - to an age inappropriate frequency and magnitude - materially impairing normal functioning (APA 2013). Adult ADHD is well-established in scientific literature (Barkley et al. 2008; Kessler et al. 2005, 2007) and is known to affect organizations and vocational behavior (Bozionelos and Bozionelos 2013; de Graaf et al. 2008; Halbesleben et al. 2013; Kessler et al. 2009).

Like other disorders, ADHD is diagnosed by a licensed clinician (such as a clinical psychologist or psychiatrist), based on a battery of psychological tests and other data. It also requires differential diagnosis, meaning that the clinician must judge that the behavior and impairment consistent with ADHD is not attributable to another condition or cause (e.g., mania, substance abuse, or say distractibility and impulsivity due to other reasons such as stress, a lack of sleep, or being in the midst of a difficult divorce). Suffice to say, there is no single test, let alone any simple psychometric measure, able to determine if an individual has ADHD.

ADHD is, by definition, a clinical construct and disorder, rooted in extensive clinical literature, which over the past $30+$ years has established the validity 
condition (APA 2013; Goldman et al. 1998) and the vast majority of its effects. Consistent with traditional clinical psychology and psychiatry, in the clinical literature, ADHD is considered inherently pathological.

\subsection{ADHD in organizational scholarship}

In terms of the emerging management and entrepreneurship literature involving ADHD, recent studies have relaxed the need to empirically consider the actual condition of ADHD (i.e., individuals with the disorder) and instead have taken a disposition-type approach (with two exceptions subsequently elaborated). There are good and pragmatic reasons for this. The non-clinical consideration of a clinical construct has allowed empirically tractable investigations and uncovered significant, non-obvious findings, such as the positive association between ADHD-type behavior and entrepreneurship.

There are two noteworthy exceptions. First, the recent study of Wiklund, Patzelt, and Dimov (2016) illustrates and provides insight into how 14 Swedish entrepreneurs with ADHD "behave." Their findings demonstrate the entrepreneurial relevance of having ADHD. In line with its qualitative design and contribution, the study cannot speak to - but further motivates - the need to understand whether there is a significant positive connection between ADHD and entrepreneurship, starting with whether ADHD significantly increases the likelihood of venturing. The second (partial) exception comes from Verheul et al. (2016) linking individuals' continuous scores on an ADHD screener (the ASRS v1.1) to their self-employment status in two datasets. Specifically, Verheul et al. (2016) performed a sensitivity analysis where individuals were screened positive or negative for ADHD based on their ASRS score. Linking the dichotomous screening variable to self-employment, the authors found the positive association between ADHD (type behavior) and selfemployment held.

For organizational research involving ADHD to advance, however, there is an issue. While empirically not studying the condition of ADHD, extant entrepreneurship research imported ADHD from the clinical literature, including a short screening tool ${ }^{1}$ for identifying individuals

\footnotetext{
${ }^{1}$ Unlike self-report psychometric scales commonly used in management research to measure latent non-clinical constructs, the ASRS (Kessler et al. 2005, 2007) was designed and validated to simply screen individuals for subsequent in-person evaluation by practicing clinicians.
}

for possible clinical referral/evaluation. We appreciate that this can be entirely appropriate, depending on the research question, the state of (incipient) knowledge, and the research constraints. The present concern and hitherto limitation is the absence of a large-scale basis to consider whether the reported connection with entrepreneurship is true if considering attention deficit/hyperactivity disorder. Thus, the unresolved issue with the extant theory and research, suggesting a positive ADHD — entrepreneurship link, is that it has been built on and is fundamentally grounded in, the clinical literature involving a clinical construct and using a screening tool for the condition of ADHD, without yet comparing individuals with the condition and those without.

Toward building a sound literature, we need to understand if the recently suggested positive connection between ADHD and entrepreneurship is veridical when considering the condition of ADHD, i.e., operationalizing it consistent with its definition as a diagnosed condition/disorder. Based on the empirical and theoretical origins of ADHD, finding a positive link between the diagnosed condition and entrepreneurship would substantially bolster the emerging conversation. Specifically, this would validate recent entrepreneurship theory and findings which, despite involving clinical literature, have not tested or found a significant link between attention deficit/hyperactivity disorder and entrepreneurship. Thus, extending recent research that has examined a behavioral disposition that at one end of the spectrum might be indicative of ADHD (Lerner 2016; Thurik et al. 2016; Verheul et al. 2015, 2016; Wiklund et al. 2017), true to the grounding literature and ADHD construct, we focus on the clinical condition of ADHD.

\subsection{ADHD and entrepreneurial intentions}

Entrepreneurial intentions, typically defined as the extent to which an individual espouses intentions to form a venture/become an entrepreneur, has long been a topic of interest to entrepreneurship scholars (Krueger et al. 2000; Krueger and Brazeal 1994; Kolvereid 1996; Douglas and Shepherd 2002). Notwithstanding our ultimate interest in entrepreneurial action (versus intention), an important starting point for the scholarly consideration of a connection between ADHD and entrepreneurship is provided by Verheul et al. (2015). As the first large-scale scientific inquiry focusing on the topic, sampling of over 13,000 university students, Verheul 
et al. (2015) link a continuous indicator of ADHD-like behavior to entrepreneurial career intentions.

We begin by first asking if the apparent ADHDentrepreneurial intentions link indeed exists when considering the clinical condition. It is hitherto unclear whether, within a normal professional-oriented adult population, those who have ADHD show significantly higher entrepreneurial intentions than those without this condition. Potentially validating and extending prior research, we will empirically explore whether:

(1) Individuals with attention deficit/hyperactivity disorder (a diagnosed condition) have higher entrepreneurial intentions than those without the condition.

\subsection{ADHD and venturing/entrepreneurial action}

Individual entrepreneurial action is central to entrepreneurship; without such, "there would simply be no entrepreneurship and no new ventures" (Baron 2007, p. 167). In regard to business venturing, entrepreneurial action is often defined by nascent entrepreneurial behavior, i.e., actions associated with business start-up such as opportunity development, making a prototype, and attempting to acquire start-up resources (Gartner, Carter, and Reynolds 2004; Reynolds et al. 2004). As there are myriad potential start-up behaviors, a straightforward indicator of whether entrepreneurial action has commenced is whether an individual is in the process of attempting to start or is already running a venture (e.g., Reynolds et al. 2004).

Considering ADHD as a clinical condition affecting individual behavior, we acknowledge that it could have opposing effects on one's propensity to undertake entrepreneurial action (i.e., to venture). Although entrepreneurship is generally perceived to involve risky, complex, and innovative activities (something typically attractive to individuals with ADHD), the reality of starting a business may be far less exciting or motivating. In particular, starting a firm involves many tasks that are formal, protracted, administrative, and require attention to mundane detail (e.g., Lerner et al. 2018b). Individuals with ADHD tend to struggle with such activities and also perceive them as less attractive (Barkley 1997). Thus, when it comes to starting a venture and associated activities requiring sustained attention to details, individuals with ADHD may be apt to procrastinate such action or be otherwise distracted by more stimulating activities (including thinking about other opportunities/venture ideas). Following this line of reasoning, the classical pathological perspective on ADHD would suggest that individuals with ADHD may be less likely to venture, compared to individuals without ADHD.

Alternatively, considering that entrepreneurship requires an action orientation (Frese 2009; Sarasvathy 2001) and given that unfettered (even impulsive) action is central to ADHD (APA 2013), the opposite may be true. In individuals with ADHD "act first, think later" behavior prevails, meaning action itself is often pre-potent (i.e., will be expressed in the absence of top-down restraint) (Barkley 1997). This suggests that, at least for experimenting with entrepreneurship, those with ADHD may very well act without much or any forethought or consideration of potential consequences. In this respect, ADHD's disinhibition (Barkley 1997; Lerner 2016) promotes action. Consistent with this, Wiklund et al. (2016) document considerable entrepreneurial activity in their study of 14 entrepreneurs with ADHD. Likewise, in their sensitivity analysis, Verheul et al. (2016) find a positive link between a dichotomized score on the ASRS v1.1 screener and self-employment. Though the latter can be considered stricter than using continuous ASRS scores, the ADHD diagnostic status was entirely unknown. That is, a positive dichotomous score does not mean an individual has $\mathrm{ADHD}$, but rather signifies that further evaluation by a clinician may be appropriate. Hence, neither the recent extant studies nor the extensive popular press provides conclusive empirical evidence of the central question whether ADHD increases (or decreases) the probability of venturing/entrepreneurial action.

Appreciating the ambivalent nature of ADHD (Lerner et al. 2018b), we note that early-stage venturing primarily involves initiating entrepreneurial action. Consequently, we offer but at the same time question the notion that individuals with ADHD - a clinical disorder - are more likely than others to venture. We will empirically examine whether:

(2) Individuals with attention deficit/hyperactivity disorder (a diagnosed condition) are more likely to venture/engage in entrepreneurial action than those without the condition. 


\section{Method}

To examine whether the positive $A D H D$-entrepreneurship connection suggested by recent studies is in fact true when taking into account the clinical disorder, a large-scale study was undertaken. The purpose was to provide a basic straightforward examination of the connection between the condition of ADHD (independent variable) and entrepreneurial intentions (dependent variable 1) as well as entrepreneurial action/venturing (dependent variable 2). We were not interested in full-time entrepreneurs or employees - but rather focused on a population that is heterogeneous in terms of venturing activity (distinguishing between nascent actors and nonactors) as well as career intentions (distinguishing between individuals with and without intentions). Accordingly, and following Verheul et al. (2015), we sampled about 9800 university students who participated in GUESSS Netherlands 2014. Comparing the Dutch sample with the global GUESSS sample, reported in Sieger et al. (2014), our sample was representative in terms of age, gender, management students, and the prevalence of self-employed parents. $^{2}$

In relation to the research question, this sample is not intended to proxy some other population such as entrepreneurs, and offers a number of advantages. Given the nature of the sample and age of the respondents, the inquiry offers the advantage of capturing individuals prior to the possibility of being forced into entrepreneurship, and prior to selection and sampling biases that would be present in older workers. On a related note, it is important to acknowledge that individuals with ADHD are less likely to attend university (Barkley et al. 2008) and may be pushed into entrepreneurship via struggles with conventional employment (Parker, 2018, chapters 2 and 5). Thus, if significant results positively linking ADHD to entrepreneurship are found, they may understate what would be the effect in the general population. Hence, with the research question about whether in fact the condition of ADHD is linked to an increased entrepreneurial propensity (and not about providing a specific parameter estimate of a wellestablished effect generalizable to the overall population or providing insight into mechanisms underlying a link),

\footnotetext{
2 The Global University Entrepreneurial Spirit Students' Survey (GUESSS) is a dataset collected by an international research consortium examining career aspirations of students in higher education. For more information, refer to www.guesssurvey.org.
}

the sample likely offers a conservative test of the fundamental relationship in question.

The data collection included the following variables: attention deficit/hyperactivity disorder-yes/no to whether the individual had the diagnosed condition of $\mathrm{ADHD}^{3}$; entrepreneurial intentions based on Linan and Chen (2009) and for robustness and replication also operationalized dichotomously with post-secondary career intention (Verheul et al. 2015); venturing/entrepreneurial action, operationalized as whether the individual was in the process of starting or already running a venture; and covariate/control variables (gender, age, self-employed parents, academic performance, management as field of study). The latter were included based on their consistency with prior entrepreneurship research (Verheul et al. 2015; Parker, 2018, chapters 2 and 5).

In terms of $\mathrm{ADHD}, 4.2 \%(n=411)$ reported having the diagnosed condition. This is comparable to the adult ADHD community prevalence rate of $5 \%$ in the Netherlands (de Graaf et al. 2008) and more broadly to the $3.4 \%$ across 10 countries according to World Health Organization studies (de Graaf et al. 2008). That said, the following issues may arise when collecting the data. First, there is the possibility of under-reporting: Some individuals with ADHD may falsely report that they do not have the condition, for example because they fear stigmatization. Such false-negatives would reduce an already very minor base rate and add noise to the empirical testing - increasing the likelihood of null effects (and type-II error), and decreasing the likelihood of significant results. Second, in terms of possible overreporting, there was no reason for undiagnosed individuals to falsely report an ADHD diagnosis in the data collection. Also, the rate of $4.2 \%$ does not suggest an over-reporting problem. Third, undiagnosed individuals

\footnotetext{
$\overline{3 \text { ADHD is not }}$ seen or diagnosed as a temporary condition; it is associated with genetics and enduring neurological differences (physical brain-structure and neurotransmitters). Individuals previously diagnosed that may no longer meet diagnostic criteria, whether per taking medication or for other reasons, are often considered in-remission. In relation to the current research, attempting to separate ADHDdiagnosed individuals fully meeting diagnostic criteria at the time of data collection and those not meeting full diagnostic criteria at that moment was neither realistic (as it would require $n=411$ individual clinical evaluations by psychiatrists or clinical psychologists), nor was it considered essential for our basic research question. Nonetheless, supplemental analyses are provided examining ADHD-type symptoms at the time of data collection.
} 
who would qualify for a diagnosis do not lead to spurious positive results but rather would make any true positive effect more difficult to detect. Finally, it is possible that some of the diagnosed individuals take ADHD medication; the current question however is if there is a significant link between the ADHD and entrepreneurship (regardless of whether a diagnosed individual is medicated). Furthermore, any significant results would not be an artifact of not controlling for whether a diagnosed individual was taking medication. Finally, in relation to possible use of medication, our study is consistent with the recent studies cited that refrain from attempting to capture and control for medication use. In summary, considering the above, any significant findings would likely be conservative in nature.

For straightforward tests of whether ADHD significantly increased the likelihood of entrepreneurial intentions and actions, ordinary least squares and logistic regressions were run-according to the nature of the dependent variable (continuous or dichotomous, respectively). In addition, we ran $t$ tests examining potential differences between subgroups.

\section{Results}

The following are the results of the large-scale empirical inquiry conducted. Table 1 presents the descriptive statistics and correlations.

Tables 2 and 3 present the results of the regression analyses. As Table 2 indicates, individuals with an ADHD diagnosis showed significantly higher entrepreneurial intentions. This was the case whether operationalized following Linan and Chen (2009) as a continuous variable, or following Verheul et al.'s (2015) dichotomous variable. In terms of the readily interpretable latter, individuals with ADHD were approximately 1.7 times (i.e., 60-80\%) more likely to have entrepreneurial intentions (models $1 \mathrm{c}$ and 1d, odd ratios: 1.8, 1.6). This extends the findings of Verheul et al. (2015), assuaging the clinical-but-non-clinical disjuncture of prior research and validating the veridicality of the previously suggested positive link with intentions.

Even more interestingly, Table 3 reveals a significant positive link between ADHD diagnosis and venturing/ entrepreneurial action. In particular, having ADHD increases the odds of venturing by almost $100 \%$. The results indicate that university enrolled adults with ADHD are almost two times more likely to initiate entrepreneurial action than those without ADHD (models 2a and 2b, odd ratios: $1.9,1.8$ ). In other words, among individuals who still have to make a vocational choice (and have yet to be pushed into venturing out of necessity/failure in wage employment), those with the disorder of ADHD were not less or similarly likely to venture than those without the disorder, but rather were significantly more likely to venture. Considering that individuals with ADHD are less likely to attend post-secondary education and may be pushed out of conventional employment (e.g., Barkley et al. 2008), these results may understate the true effect size relative to the overall population. Considering the design and nature of the sample, these results do not speak to venturing outcomes, nor stand to provide generalizable parameter estimates. Simply, the results provide a straightforward test and clear support for a positive link between ADHD and entrepreneurship, attributable to individual choice versus a vocation of last resort.

These results extend prior research and establish a potential upside or non-pathological effect of a clinical disorder. Given the research question, the significant positive effect of ADHD and the high associated odds ratios, indicative of a large effect, are the focus.

The low total variance explained rightfully indicates that there are myriad factors influencing whether an individual is interested and will engage in venturing. Moreover, given the representative but minority frequency of individuals with ADHD diagnoses in the sample, the overwhelming majority of the sample does not have $\mathrm{ADHD}$ and, accordingly, low $R^{2} \mathrm{~s}$ are not just normal but mathematically ought to be observed. ${ }^{4}$ If around $4 \%$ of a sample has a dichotomous condition, and many individuals without the disorder also venture, looking at $R^{2}$ is analogous to, for example, examining how much of the total probability of engaging in Corporate Acquisition activity is explained by a relatively uncommon predictor such as CEO ADHD. However, the research objective is not about explaining the broad preponderance of the dependent variable, but instead is about understanding whether a theoretically meaningful, yet relatively low base rate,

\footnotetext{
$\overline{{ }^{4} \text { Low } R^{2} \mathrm{~s} \text { are to }}$ be expected based on very limited variance in ADHD as a dichotomous predictor, especially when attempting to predict a relatively infrequent dichotomous variable. Any relatively minority (i.e., low base rate) feature, whether a clinical condition or otherwise, will not explain the vast preponderance of variance in a human activity such as entrepreneurship - considering such (as a dependent variable) is also engaged in by some of the overwhelming majority - that is, those without the low-frequency dichotomous feature.
} 
Table 1 Descriptive statistics and correlations

\begin{tabular}{|c|c|c|c|c|c|c|c|c|c|c|c|c|}
\hline & Mean & SD & Min. & Max. & 1 & 2 & 3 & 4 & 5 & 6 & 7 & 8 \\
\hline 1. ADHD diagnosis & .04 & .20 & 0 & 1 & & & & & & & & \\
\hline 2. Self-employed parent(s) & .31 & .46 & 0 & 1 & .02 & & & & & & & \\
\hline 3. Academic performance & 4.92 & .93 & 1 & 7 & -.04 & .02 & & & & & & \\
\hline 4. Management study & .21 & .41 & 0 & 1 & -.01 & .06 & .02 & & & & & \\
\hline 5. Age & 22.40 & 3.39 & 17 & 40 & .04 & -.06 & .03 & -.05 & & & & \\
\hline 6. Gender $($ male $=1)$ & .38 & .49 & 0 & 1 & .04 & -.01 & -.005 & .09 & .08 & & & \\
\hline 7. Entrepreneurial intentions (dichotomous) & .05 & .21 & 0 & 1 & .03 & .03 & .000 & .03 & .05 & .09 & & \\
\hline 8. Entrepreneurial intentions (continuous) & 3.28 & 1.76 & 1 & 7 & .03 & .14 & .005 & .18 & -.03 & .16 & .25 & \\
\hline 9. Venturing/Entrepreneurial action & .13 & .33 & 0 & 1 & .05 & .08 & .03 & .06 & .05 & .18 & .43 & .37 \\
\hline
\end{tabular}

$N=9749$; All correlations $\geq|.02|$ are significant at $5 \%$. All correlations $\geq|.03|$ are significant at $1 \%$

Dichotomous variables are dummy coded $(0=$ no, $1=$ yes $)$

Table 2 Explaining entrepreneurial intentions (OLS and logistic regression results)

\begin{tabular}{|c|c|c|c|c|}
\hline \multirow[t]{2}{*}{ Dependent variable } & \multicolumn{4}{|c|}{ Entrepreneurial Intentions } \\
\hline & \multicolumn{2}{|c|}{ Continuous DV (Linan and Chen 2009) } & \multicolumn{2}{|c|}{ Dichotomous DV (Verheul et al. 2015) } \\
\hline \multicolumn{5}{|l|}{ Model } \\
\hline & 1a (main-effect) & $1 \mathrm{~b}$ (with controls) & 1c (main-effect) & $1 \mathrm{~d}$ (with controls) \\
\hline Predictor variables & \multicolumn{2}{|c|}{$\begin{array}{l}\text { B Estimates } \\
\text { (standard errors) }\end{array}$} & \multicolumn{2}{|c|}{$\begin{array}{l}\text { Odds ratios: } \operatorname{Exp}(\mathrm{B}) \\
\text { (95\% confidence interval) }\end{array}$} \\
\hline Constant & $\begin{array}{l}3.268^{* * * *} \\
(0.019)\end{array}$ & $\begin{array}{l}3.109 * * * \\
(0.152)\end{array}$ & $0.048 * * *$ & $0.009 * * *$ \\
\hline Age & & $\begin{array}{l}-0.015^{*} \\
(0.005)\end{array}$ & & $\begin{array}{l}1.053 * * * \\
(1.028-1.078)\end{array}$ \\
\hline Gender $($ male $=1)$ & & $\begin{array}{l}0.536 * * * \\
(0.037)\end{array}$ & & $\begin{array}{l}2.151 * * * \\
(1.778-2.602)\end{array}$ \\
\hline Self-employed parent(s) & & $\begin{array}{l}0.495 * * * \\
(0.039)\end{array}$ & & $\begin{array}{l}1.429 * * * \\
(1.177-1.736)\end{array}$ \\
\hline Academic performance & & $\begin{array}{l}0.001 \\
(0.019)\end{array}$ & & $\begin{array}{l}0.998 \\
(0.904-1.101)\end{array}$ \\
\hline Management study & & $\begin{array}{l}0.688 * * * \\
(0.044)\end{array}$ & & $\begin{array}{l}1.322 * * \\
(1.068-1.636)\end{array}$ \\
\hline ADHD diagnosis & $\begin{array}{l}0.231 * \\
(0.095)\end{array}$ & $\begin{array}{l}0.200 * \\
(0.092)\end{array}$ & $\begin{array}{l}1.802 * * \\
(1.247-2.605)\end{array}$ & $\begin{array}{l}1.625 * \\
(1.119-2.360)\end{array}$ \\
\hline Model & & & & \\
\hline$R^{2}$, Nagelkerke $R^{2}$ & $.001 *$ & $.071 * * *$ & $.003 * *$ & $.036^{* * *}$ \\
\hline F-statistic, Chi-square & $5.970^{*}$ & $115.768^{* * *}$ & $8.511^{* *}$ & $113.849^{* * *}$ \\
\hline-2 Log likelihood & & & 3770.50 & 3631.53 \\
\hline$N$ & 9211 & 9124 & 9869 & 9770 \\
\hline
\end{tabular}

Significance levels (2-tailed) are indicated as follows: $*=0.05 ; * *=0.01 ; * * *=0.001$. Differences in reported $N$ s are per missing data from some subjects (SPSS pairwise exclusion) 
Table 3 Explaining venturing/ entrepreneurial action (logistic regression results)
Significance levels (2-tailed) are indicated as follows: $* *=0.01$; $* * *=0.001$. Differences in reported $N \mathrm{~s}$ are per missing data from some subjects (SPSS pairwise exclusion)

\begin{tabular}{|c|c|c|}
\hline Dependent Variable & \multicolumn{2}{|c|}{ Venturing/Entrepreneurial Action $($ yes $=1$ ) } \\
\hline \multicolumn{3}{|l|}{ Model } \\
\hline & 2a (main-effect) & $2 \mathrm{~b}$ (with controls) \\
\hline Predictor variables & \multicolumn{2}{|c|}{$\begin{array}{c}\text { Odds ratios: } \operatorname{Exp}(\mathrm{B}) \\
\text { (95\% confidence interval) }\end{array}$} \\
\hline Constant & \multirow[t]{3}{*}{$0.141 * * *$} & $0.017 * * *$ \\
\hline Age & & $\begin{array}{l}1.039 * * * \\
(1.022-1.057)\end{array}$ \\
\hline Gender $($ male $=1)$ & & $\begin{array}{l}2.709 * * * \\
(2.394-3.066)\end{array}$ \\
\hline Self-employed parent(s) & & $\begin{array}{l}1.665^{* * *} \\
(1.469-1.888)\end{array}$ \\
\hline Academic performance & & $\begin{array}{l}1.111 * * \\
(1.041-1.187)\end{array}$ \\
\hline Management study & & $\begin{array}{l}1.355^{* * * *} \\
(1.179-1.558)\end{array}$ \\
\hline ADHD Diagnosis & $\begin{array}{l}1.926^{* * *} \\
(1.510-2.457)\end{array}$ & $\begin{array}{l}1.792 * * * \\
(1.393-2.305)\end{array}$ \\
\hline \multicolumn{3}{|l|}{ Model } \\
\hline Nagelkerke $R^{2}$ & $.005^{* * *}$ & $.077^{* * *}$ \\
\hline Chi-square & $24.795^{* * *}$ & $412.292 * * *$ \\
\hline-2 Log likelihood & 7513.90 & 7037.85 \\
\hline$N$ & 9869 & 9770 \\
\hline
\end{tabular}

predictor indeed has a significant and material effect on the probability of nascent venturing. As such, the highly significant readily interpretable odds ratios indicative of a large effect are informative and meaningful. The results indicate that not only is the effect of ADHD statistically significant, it also materially increases the odds of venturing. It increases the likelihood of venturing by almost $100 \%$ (79\% with covariates), which is comparable to other well-established predictors of entrepreneurship such as having self-employed parents (model 2b). Considering the research design and myriad other covariates of potential interest, the results do not illuminate causal pathways; rather, the results indicate that further research into how and why is warranted and apt to be fruitful.

\subsection{Supplemental analyses}

Despite the theoretical and empirical evidence of the enduring nature of ADHD (after diagnosis), particularly in relation to our research question, we nonetheless ran supplemental analyses. Acknowledging that ADHD diagnosis occurred prior to the time of data collection, we examine whether the diagnosed individuals still report to have symptoms by assessing respondents' scores on impulsivity and mental restlessness, both of which are associated with adult ADHD (Barkley 1997; Weyandt et al. 2003). The abbreviated scale for impulsivity, supported by Webster and Crysel (2012), was composed of the most appropriate three items of the Zuckerman et al.' (1993) longer scale. The abbreviated scale for mental restlessness was composed of the four primary items of the internal restlessness factor/scale (Weyandt et al. 2003). Examining the entire sample $(N=9869)$, ADHD-diagnosed individuals endorsed mental restlessness (mean: 4.8 on 7-point scale) and impulsivity (mean: 4.3 on 7-point scale) and scored significantly higher on both compared to non-diagnosed individuals $\left(\mathrm{t}_{1,449=10.6}\right.$ and $\mathrm{t}_{1,443=1} 12.4$, respectively; equal variances not assumed, $p<.001)$. The results were similar within the subset of venturers $(n=579)$. Here, the diagnosed individuals endorsed mental restlessness (mean: 4.8 on 7-point scale) as well as impulsivity (mean: 4.6 on 7-point scale) and scored significantly 
higher on both than non-diagnosed individuals $\left(\mathrm{t}_{1,51=3.1}\right.$

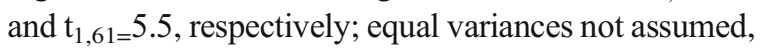
$p<.001)$.

\section{Discussion}

The present paper extends recent entrepreneurship research, using a strict conceptualization and measurement of ADHD, that is, ADHD as a clinically diagnosed condition. We find that, in spite of ADHD's downsides and individuals having sufficient disorder as to be clinically diagnosed, ADHD positively rather than negatively affects the likelihood of venturing. Building on prior research, this elucidates that a dark and pathologized condition can serve as a wellspring for entrepreneurial action. Certainly, future research is needed, examining entrepreneurial action at a much more granular level, and the eventual outcomes of such action beyond the nascent stage (Lerner et al. 2018b). Nonetheless, without entrepreneurial action "there would simply be no entrepreneurship and no new ventures" (Baron 2007, p. 167). Furthermore, given the myriad unproductive and destructive behaviors also linked to ADHD, entrepreneurial action may be a constructive outlet regardless of whether a venture is ultimately founded and successful. Finally, understanding whether there is scientific evidence of a positive link between the clinical condition of ADHD and initiating entrepreneurship provides a basis for embarking on research attempting to capture more complex dynamics and outcomes.

This complements the qualitative findings of Wiklund et al. (2016), as well as Verheul et al.'s (2016) quantitative findings based on dichotomized ASRS v1.1 scoring. Based on our large-scale quantitative testing that did not preselect on either ADHD status or observable entrepreneurs, and prior to the possibility of entrepreneurship as last resort, we find evidence that individuals diagnosed with ADHD are more likely to take entrepreneurial action than individuals without such a diagnosis. It suggests the potential adaptiveness of the unequivocally pathological-going beyond behavioral traits such as impulsivity to a full-blown clinical disorder/diagnosis. Our findings empirically advance emergent theory involving ADHD and clinical conditions in general, and are in line with recent research suggesting alternative logics for entrepreneurial action (Lerner et al. 2018a).

\subsection{Cautions and limitations}

It is important to underscore that entrepreneurial action and performance are not synonymous. The linkage found between ADHD and venturing/ entrepreneurial action should not be conflated, nor interpreted as a positive link with venture performance. The present study cannot speak to the effect of ADHD on venture performance or other entrepreneurial outcomes. Rather, it suggests the need and opportunity for future research in this direction. Since potential venturing outcomes include everything from success to catastrophic loss (with negative outcomes more likely if inattentive to foreseeable pitfalls or if impulsively spending through savings, high-interest debt, or home equity), future research is needed to more fully understand the connection between ADHD and venturing, including if entrepreneurship is on average a good fit for individuals with ADHD. Suffice to say, the connection between ADHD and later stages of organizing, profitability, and growth are yet unknown - and it is unlikely to be entirely rosy or dark (Lerner et al. 2018b).

Our study has several limitations. The simple, straightforward design and sample used were appropriate for the critical research question of whether actual ADHD and the likelihood of entrepreneurial action are positively connected. The resultant coefficient estimates, while likely conservative in nature for aforementioned reasons, should however not be presumed to be broadly generalizable to other populations (Antshel 2017; Canits et al. 2018). At an even deeper level, it is important to recall that generalizability is not per se a property of any empirical study, but rather is a question of whether a theoretical relationship generalizes across empirical contexts (Zelditch 1969). As our findings quite strongly ground prior research and establish the central theorized relationship, they indicate the fruitfulness of future research involving other populations, other designs, and more complex theory. 


\subsection{Implications and conclusions}

The present work foments and contributes to various scholarly conversations, particularly those involving mental health or ADHD and entrepreneurship (Lerner 2016; Lerner et al. 2018b; Thurik et al. 2016; Verheul et al. 2015, 2016; Wiklund et al. 2016). It also serves as a basis for future research. For example, the finding that individuals with ADHD are almost two times more likely to venture indicates the merit of further studies on ADHD and venturing outcomes. This is particularly so once considering the otherwise squandered human capital, the costs of business failure, and/or the many adverse outcomes associated with unchanneled adult ADHD (such as absenteeism, unemployment, substance abuse, incarceration).

Bolstered by the findings of our large-scale quantitative inquiry, ADHD has implications for organizational research, practice, and policy. Research implications include highlighting the need for further study of contextual factors determining under which conditions ADHD is a strength or a weakness, and is adaptive or counter-productive in venturing. In regard to practice and policy, understanding that mental health, and ADHD in particular, has dark and bright sides for entrepreneurship, has various implications. For example, it suggests the opportunity for research to help educators, clinicians, and even organizations focus on strengths (such as a willingness to act, an imperturbable focus on activities of interest) and compensate for weaknesses (such as distractibility and poor attention to detail in mundane activities). More generally, it suggests the continued opportunity for considering other predictors potentially seen as aberrant in respect to entrepreneurship (e.g., Hmieleski and Lerner 2016; Wiklund et al. 2018).

Overall, the present work contributes to theory by grounding recent research linking ADHD and entrepreneurship with a large-scale quantitative examination that squarely tests the effect of attention deficit/hyperactivity disorder. In concert with other studies, the work establishes an emergent entrepreneurship literature on ADHD. In doing so, it attests to broader emerging theory that generally suggests the relevance of clinical or otherwise dark constructs in entrepreneurship.
Open Access This article is distributed under the terms of the Creative Commons Attribution 4.0 International License (http:// creativecommons.org/licenses/by/4.0/), which permits unrestricted use, distribution, and reproduction in any medium, provided you give appropriate credit to the original author(s) and the source, provide a link to the Creative Commons license, and indicate if changes were made.

\section{References}

American Psychiatric Association (APA) (2013). Diagnostic and statistical manual of mental disorders (DSM-5). American Psychiatric Publishing.

Antshel, K. M. (2017). Attention deficit/hyperactivity disorder (ADHD) and entrepreneurship. Academy of Management Perspectives. https://doi.org/10.5465/amp.2016.0144.

Archer, D. (2014). ADHD: the entrepreneur's superpower. Forbes Magazine Online. http://www.forbes.com/sites/dalearcher/2014 /05/14/adhd-the-entrepreneurs-superpower. Retrieved 11/22 $/ 2016$.

Barkley, R. A. (1997). Behavioral inhibition, sustained attention, and executive functions: constructing a unifying theory of AD/HD. Psychological Bulletin, 121(1), 65-94.

Barkley, R.A., Murphy, K.R., Fischer, M. (2008). ADHD in adults: what the science says. Guilford, New York.

Baron, R. A. (2007). Behavioral and cognitive factors in entrepreneurship: entrepreneurs as the active element in new venture creation. Strategic Entrepreneurship Journal, 1(1-2), 167182.

Baron, R. A., Hmieleski, K. M., \& Henry, R. A. (2012). Entrepreneurs' dispositional positive affect: the potential benefits - and potential costs - of being "up". Journal of Business Venturing, 27, 310-324.

Bozionelos, N., \& Bozionelos, G. (2013). Attention deficit/ hyperactivity disorder at work: does it impact job performance? Academy of Management Perspectives, 27(3). https://doi.org/10.5465/amp.2013.0107.

Canits, I., Bernoster, I., Mukerjee Nath, I., Bonnet, J., Rizzo, U., \& Rosique, M. (2018). ADHD (attention-deficit/hyperactivity) symptoms and academic entrepreneurial preference: is there an association? Small Business Economics, this issue.

Cardon, M., Foo, M.-D., Shepherd, D., \& Wiklund, J. (2012). Exploring the heart: entrepreneurial emotion is a hot topic. Entrepreneurship Theory and Practice, 36(1), 1-10.

de Graaf, R., Kessler R. C., Fayyad, J. et al. (2008). The prevalence and effects of adult attention deficit/hyperactivity disorder (ADHD) on the performance of workers: results from the WHO World Mental Health Survey Initiative. Occupational and Environmental Medicine; 65:(835)

Douglas, E. J., \& Shepherd, D. A. (2002). Self-employment as a career choice: attitudes, entrepreneurial intentions, and utility maximization. Entrepreneurship Theory and Practice, 26(3), 81-90.

Frese, M. (2009). Towards a psychology of entrepreneurship: an action theory perspective. Foundations and Trends in Entrepreneurship, 5(6), 437-496. https://doi.org/10.1561 10300000028. 
Gartner, W. B., Carter, N. M., \& Reynolds, P. D. (2004). Business start-up activities. In W. B. Gartner, K. G. Shaver, N. M. Carter, \& P. D. Reynolds (Eds.), Handbook of entrepreneurial dynamics: the process of business creation in contemporary America (pp. 285-298). Thousand Oaks: Sage.

Gielnik, M. M., Uy, M. A., Funken, R., \& Bischoff, K. M. (2017). Boosting and sustaining passion: a long-term perspective on the effects of entrepreneurship training. Journal of Business Venturing, 32(3), 334-353.

Goldman, L.S., Genel, M., Bezman, R.J. and Slanetz, P.J. (1998) Diagnosis and Treatment of Attention Deficit Hyperactivity Disorder in Children and Adolescents. Journal of the American Medical Association, 279, 1100-1107. https://doi. org/10.1001/jama.279.14.1100.

Halbesleben, J. R. B., Wheeler, A. R., \& Shanine, K. K. (2013). The moderating role of attention-deficit/hyperactivity disorder in the work engagement-performance process. Journal of Occupational Health Psychology, 18(2), 132-143.

Hmieleski, K. M., \& Baron, R. A. (2008). Regulatory focus and new venture performance: a study of entrepreneurial opportunity exploitation under conditions of risk versus uncertainty. Strategic Management Journal, 2, 285-299.

Hmieleski, K. M., \& Lerner, D. A. (2016). The dark triad and nascent entrepreneurship: an examination of unproductive versus productive entrepreneurial motives. Journal of Small Business Management. https://doi.org/10.1111/jsbm.12296.

Kessler, R. C., Adler, L., Ames, M., Demler, O., Faraone, S., Hiripi, E., Howes, M. J., Jin, R., Secnik, K., Spencer, T., Ustun, T. B., \& Walters, E. E. (2005). The World Health Organization Adult ADHD Self-Report Scale (ASRS). Psychological Medicine, 35(2), 245-256.

Kessler, R. C., Adler, J., Gruber, M. J., Sarawate, C. A., et al. (2007). Validity of the World Health Organization Adult ADHD Self-Report Scale (ASRS) screener in a representative sample of health plan members. International Journal of Methods in Psychiatric. Research, 16(2), 52-65.

Kessler, R. C., Lane, M., Stang, P. E., \& Van Brunt, D. L. (2009). The prevalence and workplace costs of adult attention deficit hyperactivity disorder in a large manufacturing firm. Psychological Medicine, 39, 137-147.

Kolvereid, L. (1996). Prediction of employment status choice intentions. Entrepreneurship Theory and Practice, 21(1), $47-57$.

Krueger, N. F., \& Brazeal, D. V. (1994). Entrepreneurial potential and potential entrepreneurs. Entrepreneurship Theory and Practice, 18(3), 91-104.

Krueger, N. F., Reilly, M. D., \& Carsrud, A. L. (2000). Competing models of entrepreneurial intentions. Journal of Business Venturing, 15(5-6), 411-432.

Lerner, D. (2016). Behavioral disinhibition and nascent venturing: relevance and initial effects on potential resource providers. Journal of Business Venturing, 31(2), 234-252.

Lerner, D., Hunt, R., \& Dimov, D. (2018a). Action! moving beyond the intendedly-rational logics of entrepreneurship. Journal of Business Venturing, 33(1), 52-69. https://doi. org/10.1016/j.jbusvent.2017.10.002.

Lerner, D., Hunt, R., \& Verheul, I. (2018b). Dueling Banjos: harmony and discord between ADHD and entrepreneurship. Academy of Management Perspectives. https://doi. org/10.5465/amp.2016.0178.
Lerner, D., Hatak, I., \& Rauch, A. (2018c). Deep roots? Behavioral inhibition and behavioral activation system (BIS/BAS) sensitivity and entrepreneurship. Journal of Business Venturing Insights, 9, 107-115. https://doi. org/10.1016/j.jbvi.2018.02.005.

Linan, F., \& Chen, Y.-W. (2009). Development and cross-cultural application of a specific instrument to measure entrepreneurial intentions. Entrepreneurship: Theory and Practice, 33(3), 593-617.

Miller, D., \& Le Brenton-Miller, I. (2016). Underdog entrepreneurs: a model of challenge-based entrepreneurship. Entrepreneurship Theory \& Practice. https://doi. org/10.1111/etap.12253.

Parker, S. C. (2018). The economics of entrepreneurship (2nd ed.). Cambridge: Cambridge University Press.

Reynolds, P., Carter, N., Gartner, W., \& Greene, P. (2004). The prevalence of nascent entrepreneurs in the United States: evidence from the panel study of entrepreneurial dynamics. Small Business Economics, 23, 263-284.

Sarasvathy, S. D. (2001). Causation and effectuation: toward a theoretical shift from economic inevitability to entrepreneurial contingency. Academy of Management Review, 26(2), 243-263.

Shane, S. 2003. A general theory of entrepreneurship: the individual-opportunity nexus. Aldershot: Edward Elgar.

Sieger, P., Fueglistaller, U., \& Zellweger, T. (2014). Student entrepreneurship across the globe: a look at intentions and activities. St. Gallen: KMU-HSG.

The Economist. (2012). In praise of misfits: why business needs people with Asperger's syndrome, attention-deficit disorder and dyslexia, June 2nd, 2012.

Thurik, A. R., Khedhaouria, A., Torrès, O., \& Verheul, I. (2016). ADHD symptoms and entrepreneurial orientation of small firm owners. Applied Psychology, 65(3), 568-586.

Tumasjan, A., \& Braun, R. (2012). In the eye of the beholder: how regulatory focus and self-efficacy interact in influencing opportunity recognition. Journal of Business Venturing, 27, 622-636.

Verheul, I., Block, J., Burmeister-Lamp, K., Thurik, R., Tiemeier, H., \& Turturea, R. (2015). ADHD-like behavior and entrepreneurial intentions. Small Business Economics, 45(1), 85101.

Verheul, I., Rietdijk, W., Block, J., Franken, I., Larsson, H., \& Thurik, R. (2016). The association between attention-deficit/ hyperactivity (ADHD) symptoms and self-employment. European Journal of Epidemiology, 31(8), 793-801. https://doi.org/10.1007/s10654-016-0159-1.

Webster, G. D., \& Crysel, L. C. (2012). "Hit me, maybe, one more time": brief measures of impulsivity and sensation seeking and their prediction of blackjack bets and sexual promiscuity. Journal of Research in Personality, 46(5), 591-598. https://doi.org/10.1016/j.jrp.2012.07.001.

Weyandt, L. L., Iwaszuk, W., Fulton, K., Ollerton, M., Beatty, N., Fouts, H., et al. (2003). The internal restlessness scale: performance of college students with and without ADHD. Journal of Learning Disabilities, 36(4), 382-389.

Wiklund, J., Patzelt, H., \& Dimov, D. (2016). Entrepreneurship and psychological disorders: how ADHD can be productively harnessed. Journal of Business Venturing Insights, 6, 14 20 . 
Wiklund, J., Yu, W., Tucker, R., \& Marino, L. (2017). ADHD, impulsivity, and entrepreneurship. Journal of Business Venturing, 32(6), 627-656.

Wiklund, J., Hatak, I., Patzelt, H., \& Shepherd, D. (2018). Mental disorders in the entrepreneurship context: when being different can be an advantage. Academy of Management Perspectives. https://doi.org/10.5465/amp.2017.0063.
Zelditch, M. (1969). Can you really study an army in the laboratory? in A sociological reader on complex organization. Holt, Rinehart, and Winston, New York, 528-539.

Zuckerman, M., Kuhlman, D. M., Joireman, J., Teta, P., \& Kraft, M. (1993). A comparison of three structural models for personality: the big three, the big five, and the alternative five. Journal of Personality and Social Psychology, 65, 757768 . 